\title{
IoT technology for Smart water system
}

\author{
Varsha Radhakrishnan and Wenyan Wu
}

\author{
Varsha Radhakrishnan \\ Faculty of Computing, \\ Engineering and Built \\ Environment \\ Birmingham City University \\ Birmingham, United Kingdom \\ varsha.radhakrishnan@mail.b \\ cu.ac.uk
}

\author{
Wenyan $\mathrm{Wu}$ \\ Faculty of Computing, \\ Engineering and Built \\ Environment \\ Birmingham City University \\ Birmingham, United \\ Kingdom \\ wenyan.wu@bcu.ac.uk
}

\begin{abstract}
A serious drop in ensuring the water quality in the distribution system is a factor that affects public health. This could lead to increase in biological and non-biological contents, change in colour and odour of the water. These contaminants cause a serious threat to the whole water ecosystem. The conventional methods of analyzing the water quality require much time and labour. So there is a need to monitor and protect the water with a real time water quality monitoring system in order to make active measurements to reduce contamination. The growth of the technology had helped in developing efficient methods to solve many serious issues in real-time. Internet of things (IoT) has achieved a great focus due to its faster processing and intelligence. This paper focuses on discussing the architecture, applications and need of IoT in water management system.
\end{abstract}

Keywords - Internet of Things, WSN, RFID, AI, Water distribution system.

\section{INDRODUCTION}

Intelligent monitoring is defined as a method which is used to monitor, control, manage and optimize the network by using different computational methods that will provide customers with relevant tools and information [1]. The internet of things (IoT) forms an important part of intelligent monitoring which connects people and devices using wireless sensor technology. It is a fast growing research area in the military, energy management, healthcare and many more.

The concept of IoT was proposed by Kevin Ashton to demonstrate a set of interconnected devices [1]. IoT makes it possible to transfer information between different electronic devices embedded with new technology. The energy management is possible using energy harvesting mechanisms, which is a method of collecting energy from natural sources such as light, vibration, pressure etc. The combination of technologies such as Wireless sensor network (WSN), Radio frequency identification (RFID), Energy harvesting(EH) and Artificial Intelligence (AI) helps IoT to flourish widely.

Water distribution system(WDS) is a very important research area that affects the economic growth of our country. WDS mainly have two issues, first is the water loss due to leakage and the second is that it is prone to contamination. It is affecting the health and safety of the people. According to the report of world health organization (WHO) in 2017, around 2.1 billion people around the world lack safe drinking water. So there is a need to ensure the water quality and wastage by using Iot to reduce such issue.
There are different traditional methods to collect water datasets to measure its quality, but managing and monitoring the data from WDS in real time is challenging as the data is heterogeneous, data collection is time-consuming, energy required for processing, coverage and connectivity of the nodes in the network. By using IoT and combining technologies such as WSN, AI and EH can be used to ensure the water quality in real time and alerts the users to take remedial measures.

In this survey, we look at the need of IoT in smart water system. In the first step, a basic architecture is selected and applied in WDS by analysing and comparing different technologies, equipment, cost and methods to build a smart water system. It reveals the need for an IoT architecture with technologies combined for water distribution system. It also takes into account of its advantages and disadvantages based on the literature review. The selection of the best choice can be identified for smart water system at the end of this step. The next step involves selection of the parameters required using IoT for water distribution. At this step, the current issues during the selection of parameters and some suitable suggestions are provided. Finally, an overview of the benefits which is necessary to implement IoT in smart water system is discussed.

The survey structure is organized as follows. Section 2 explains the basic architecture and technologies applied at each layer in IoT for water management and section 3 specifies the parameters required to identify water quality, section 4 provides the applications of IoT in water and section 5 explains the benefits of IoT in smart water system based on the architecture and concluding with section 6 .

\section{ARCHITECTURE}

There are different architectures proposed by different authors based on the type and level of security required by each application. A six layered architecture has been proposed in [2] by combining Web services, RFID and WSN whereas a five level architecture has been mentioned in [4] based on telecommunication management network. The basic and simple architecture [3] consists of three layers which are perception, network and application layer. This architecture will be used in the review paper focusing on WDS.

\section{A. Perception Layer}

The main use of the perception layer is to connect devices and collect data for processing from the IoT network. This layer consists of sensors, EH devices when applied to WDS. 
Different types of sensors are available commercially which is used to detect water monitoring in real time. A sensor network using electrochemical optical sensors [7] is one among the sensors to identify temperature, water flow, $\mathrm{pH}$ etc. Another one is kapta $3000 \mathrm{AC} 4$ to measure chlorine, temperature, pressure and conductivity of the water and it costs around 3200 pounds whereas spectro::lyser is another one to monitor colour, turbidity, COD, BTX O3 etc. with a longer range and costs about 11000 pounds. Smart water solution by libelium is another sensor in identifying water contaminants and costs around 5000 pounds [5], [6]. The choice of the water quality sensor depends upon the cost, efficiency and the selection of the water quality attributes.

Energy harvesting is a method of collecting energy from different natural sources such as light, wind, vibration etc. and converting it into electricity to power up a device or extend its battery life.

TABLE I. COMMERCIALLy AVAILABLE WATER Quality SENSORS AND THE MEASURING PARAMETERS

\begin{tabular}{|l|l|l|}
\hline Sensor & $\begin{array}{l}\text { Water quality } \\
\text { parameter }\end{array}$ & Source \\
\hline Spectro::lyser & $\begin{array}{l}\text { Turbidity, temperature, } \\
\text { pressure, colour, } \\
\text { dissolved ions, UV254 }\end{array}$ & Broeke(2005)[9] \\
\hline SmartCoast & $\begin{array}{l}\text { pH, dissolved } \\
\text { oxygen(DO), } \\
\text { conductivity, } \\
\text { temperature, turbidity, } \\
\text { phosphate, water level }\end{array}$ & $\begin{array}{l}\text { O'Flyrm et al., } \\
\text { 2007[10] }\end{array}$ \\
\hline Kapta 3000 AC4 & $\begin{array}{l}\text { Chlorine, temperature, } \\
\text { pressure, conductivity }\end{array}$ & $\begin{array}{l}\text { Mcdougle et al., } \\
\text { 2012[11] }\end{array}$ \\
\hline $\begin{array}{l}\text { SH, dissolved } \\
\text { oxygen(DO), } \\
\text { conductivity, } \\
\text { temperature, oxidation- } \\
\text { reduction potential(ORP), } \\
\text { turbidity, dissolved ions }\end{array}$ & Libelium(2014)[12] \\
\hline Lab-on-chip & $\begin{array}{l}\text { Any specific bio- } \\
\text { chemical }\end{array}$ & $\begin{array}{l}\text { Tsopela et al., } \\
\text { 2016[13] }\end{array}$ \\
\hline I::scan & Colour, turbidity, UV254 & S::can(2017)[8] \\
\hline
\end{tabular}

Energy harvesting module is an electronic device used to generate energy and manage it for the working of its connected sensors, processing and communication units [14]. Energy harvesting methods are gaining more research interest each year due to their different properties. The new energy harvesting methods and their desirable properties such as low cost, efficiency, availability and high robustness could benefit the water management system [15].

TABLE II. HARVESTING TeChNIQUES AgAinst ENERgy Produced AND COST

\begin{tabular}{|l|l|l|}
\hline $\begin{array}{l}\text { Harvesting } \\
\text { technique }\end{array}$ & Power generated & Cost \\
\hline Light (solar cell) & $15 \mathrm{~mW} / \mathrm{cm}^{2}$ & Low \\
\hline Vibration & $116 \mu \mathrm{W} / \mathrm{cm}^{3}$ & Low \\
\hline RF & $\sim 100 \mu \mathrm{W} / \mathrm{cm}^{3}$ & Medium \\
\hline Thermoelectric & $40 \mu \mathrm{W} / \mathrm{cm}^{3}$ & Low \\
\hline Electro-magnetic & $18 \mathrm{~mW} / \mathrm{cm}^{3}$ & High \\
\hline Piezo-electric & $330 \mu \mathrm{W} / \mathrm{cm}^{3}$ & High \\
\hline
\end{tabular}

The selection of the energy harvesting method is based on the type and location of the application. Kinetic, radiant, thermal and biochemical are the sources used to generate energy. The amount of energy produced by energy harvesting depends upon the pressure, flow rate and structure of the pipelines. Table 1 provides a list of the available harvesting techniques and the amount of power and cost involved in each method [15], [16], [17].

The energy harvesting methods suitable for water monitoring are the solar cell, piezo electric, electro-magnetic, fuel cell and thermo-electric. The practical implementation of solar cell seems to be difficult as the transferring of energy to underground water pipelines will be difficult whereas the fuel cell uses a chemical reaction to generate power which will be a slow process. The piezoelectric, electromagnetic and thermoelectric are the other three methods which are used widely for monitoring water pipelines [18], [19], [20]. Table 2 provides a comparison of these three techniques in the wireless network. The selection of the harvesting method was based on considering its advantages and disadvantages that were analysed during the literature [21], [22], [23].

TABLE III. COMPARISON OF HARVESTING TECHNIQUES USED IN WATER PIPELINES[20], [21], [22], [23]

\begin{tabular}{|l|l|l|}
\hline $\begin{array}{l}\text { Harvesting } \\
\text { technique }\end{array}$ & Advantages & Disadvantages \\
\hline Piezo-electric & $\begin{array}{l}\text { High efficiency, easy } \\
\text { to design, No need of } \\
\text { external voltage source }\end{array}$ & $\begin{array}{l}\text { Small leakage of } \\
\text { charge due to } \\
\text { polarization }\end{array}$ \\
\hline Electromagnetic & $\begin{array}{l}\text { Reliable, No need of } \\
\text { external voltage source }\end{array}$ & $\begin{array}{l}\text { Size bigger compared } \\
\text { to other methods, low } \\
\text { voltage load }\end{array}$ \\
\hline Thermoelectric & Lightweight, Reliable & $\begin{array}{l}\text { Difficult to design due } \\
\text { to maintain optimal } \\
\text { thermal conduction } \\
\text { coefficient, low power } \\
\text { generated }\end{array}$ \\
\hline
\end{tabular}

\section{B. Network Layer}

The network layer of IoT in WDS combines processing, managing and transmission of the data passed from the perception layer. This layer also helps in managing the network devices and communication technologies for transmission.

The communication technology is classified into two based on the range of transmission. The cellular technology is used when long-distance transmission is required by using $2 \mathrm{G}$, $3 \mathrm{G}, 4 \mathrm{G}$ [26]. The GSM, GPRS are some of the protocols used for long distance transmission. It requires more power consumption which makes them not much feasible for WDN. The short range protocols include Zigbee, 6lowpan, Radio frequency identification (RFID). The RFID uses an electronically programmed tag that is used to used to collect data [27].

The need of a programmed static tag makes it unreliable to use for measurement. The 6lowpan is an IP based protocol which can be easily connected to another IP network without any gateways. Another advantage is its low cost and power consumption. It supports both star and mesh topology. LoRa (Low Power Wide Area Network) is another protocol which gained public interest due to its low power consumption, cost and high data rate when applied in IoT and it uses the star topology. Zigbee is a widely used low power wireless 
protocol that provides low cost, security during communication. It also supports star, mesh and tree topology [26]. The advantages of 6lowpan, LoRa and Zigbee make the best choices to be used in WDS.

Another technology that could be integrated with WDS is Artificial intelligence(AI). It is defined as a system that helps in problem-solving, decision-making, data identification, processing. Adaptive Neuro fuzzy inference system is one among the new AI method to predict the wastewater quality from industries [28] whereas an adaptive network based fuzzy system is used in [29] to detect the water quality from a paper mill. Artificial neural networks (ANN) and AI algorithms are also used in the water industry to monitor and predict the water quality which provides accurate results [30].

\section{Application Layer}

The application layer manages the applications that will be used in WDS. This layer also provides user's security and privacy.

Cloud computing is one of the upcoming technology that could be used in the application layer of the WDS. Cloud computing is a solution for the storage, processing and management of heterogeneous data from different wireless devices and the cost of the service is based on the usage [31]. It can be considered as a separate layer between network and application layer. It helps IoT in storing backup data's, analysis and prediction of the received data based on each application.

\section{PARAmeters in SMART WATER System}

The parameters to detect the water quality depends on the property they exhibit and where it is applied. There are a number of parameters to detect the water quality, but monitoring all the parameters will affect the increase in workload and thereby affecting the quality of analysis. The parameters that are usually used to detect water quality in the pipeline include chemical, physical and biological properties.

\section{A. Quality Factors}

The chemical properties include $\mathrm{pH}$, dissolved oxygen and oxidation-reduction potential. The amount of acidity or alkalinity of a solution is determined using $\mathrm{pH}$. In WDS, a pH between 6 and 9 is considered normal. The ability of the water to remove the impurities by itself is called oxidation-reduction potential and a high value of oxidation-reduction potential represents the good quality of water. The dissolved oxygen is the amount of oxygen dissolved in water and it should be $0.5 \mathrm{mg} / \mathrm{L}$ for WDS [24].

The physical factors include temperature, turbidity and conductivity of water. Turbidity is the opacity or cloudiness due to the microscopic materials dissolved in the solution and it should not be less than 1NTU in WDS. High temperature affects the amount of oxygen in the water and disturbing the water quality [25].

The presence of bacteria, virus, algae and pesticides forms the biological factors affecting the water quality [25].

These are included in the basic category to determine the water quality. It is rather confusing as there aren't any international standard methods from any professional bodies for the selection of water quality parameters.

\section{B. Quantity Factors}

The water level, pressure of flow and velocity are the quantity factors that should be considered when collecting the water data. The ultrasonic sensors and flow sensors can be used to detect the velocity and identify the change in water flow [32], [33], [34].

The management of sensor data in real-time is difficult as centralized or distributed approach is used to handle them. A hybrid approach with an efficient compression technology could be used to handle and filter the real-time data based on the necessity and to reduce the cost of transmission in the network layer.

\section{Technological Factors}

The self-adapting network technology is a technological factor supporting the smart water system. The intelligent selection of stations, data fusion and forecasting to provide water quality information based on an emergency situation and make a rapid decision-making is essential for a smart water system. This could be integrated with the network layer of the architecture to achieve a more accurate real time monitoring [35].

\section{Topological Factors}

The topological factor consists of active and passive elements that form the network. The active element consists of valves, turbines and pumps through which water flow and pressure can be controlled whereas the passive element consists of pipes and reservoirs which depends on the active elements. Real-time monitoring and controlling the operations from different water sources and managing the operational cost is a major factor affecting the water system. The recent researches of different optimization methods on dynamic topology using convex programming, clustering etc. could be an added advantage to the smart water system [36].

\section{APPLiCATIONS OF IOT IN WATER}

\section{A. Smart Water System}

The smart water applications include water pipeline monitoring, water quality in open water source, smart water meter reading, IoT security for smart water system(SWS) etc. In order to ensure the integrity of customer information, security of the devices and data passed through the network, a framework and methodology were developed [37]. Water quality monitoring of open water sources was another application that was implemented using IoT devices. It helps to preserve the water quality and protect the health of the economy using low-cost devices and network virtualization [38], [39]. Another application developed due to the growth of IoT was pipe leakage detection. Different IoT devices, WSN and cloud service were used to detect and alerts the user about the pipe leakage because a good amount of water wastage is occurring through leakage [40]. Wastewater monitoring and treatment is another upcoming application in IoT to treat the wastewater and use it for household activities and thereby saving the amount of water to a great extent [41], [42].

\section{B. Smart Irrigation}

IoT based mobile applications have developed in farming to control the amount of water for crops based on the 
surrounding temperature. It also manages the whole irrigation system by smartly monitoring the soil and growth of the crops and the irrigation sprinkler will get activated whenever necessary thereby reducing the water wastage and workload [43], [44].

\section{Smart Gardening}

The smart gardening application was focused on improving the mental health of the elderly people interested in gardening which uses IoT for its implementation. It uses a set of sensors to detect the temperature, light, water, soil moisture and a mobile application to remind the need and amount of water and nutrients for the plants [45].

\section{Aquaculture System}

The aquaculture is a technique of determining and alerting users about the water quality for culturing of aquatic organisms using IoT. This application is also used to monitor the plant's environment in aquariums. It helped the aquatic farmers to recycle the water whenever they receive user alerts on their mobile devices and results in increased productivity [46].

Most of the applications mentioned above are developed in the last year which clearly depicts the growth of IoT, especially in water. There is a need for more research in water with the growth of new technologies such as IoT.

\section{BENEFITS OF IOT ARCHITECTURE IN WATER MANAGEMENT}

The following benefits of IoT help to expand the research into WDS.

\section{A. Integration of Technologies}

The integration of different technology has taken water management research to a new level. The combination of energy harvesting into IoT could resolve the energy management issues in the water distribution system. The solar cell, piezoelectric, electromagnetic and thermoelectric harvesting are the methods that could be integrated with the perception layer to enhance the smart water system. The upcoming research in micro-electro-mechanical systems (MEMS) such as piezoelectric nanowires, Lead zirconate titanate (PZT) films and multi-parameter sensor chip using iridium oxide film and X-ray photoelectron spectroscopy (XPS) analysis could also improve the research in water [47].

\section{B. Data storage, Management and Computation}

A solution to the storage issue of the wireless sensor network has been made possible by IoT-cloud combination. The use of cellular protocols, interaction aware schemes and clustering methods were used to store and manage sensor data using the cloud. Using these methods, the sensor data will be transferred into the cloud using specific algorithms and thereby provide network stability [48], [49].

Data fusion is another method to manage data in WSN. It is a method of automatically combining data from different sources that helps users to make decisions in many complicated situations. The most widely used model is Joint Director of Laboratories (JDL) which was developed to improve the cooperation and carry technological data within a group [50]. This concept has been implemented using the least square technique to identify the quality of water usage in houses. It requires more computational power and cost. The data storage and management are applied in the network layer of IoT architecture.

\section{Energy Management}

The power transfer between the sensor nodes is another technological advancement to manage energy in IoT for water distribution system. The thermal or magnetic field will be suitable for the power transfer in determining the water quality in pipelines. An energy efficient scheduling scheme for power transfer and a wireless power transfer protocol were some of the recent developments in energy management [51], [52]. The wireless power transfer protocol consists of two protocols, one for balancing the energy and the other one for checking the power of each sensor nodes for energy transfer. The research on scheduling is to reduce the energy consumption of the transmitters in software-defined wireless sensor network [51]. This technique could be implemented in the network layer to manage energy in water distribution system.

As the growth IoT is rapidly increasing every year and several IoT architectures has been introduced based on the application. The current water distribution system now uses smart devices, artificial intelligent methods and MEMS which later on could be integrated with energy harvesting methods and more IoT devices, the basic architecture seems to be inefficient to be used in water distribution system with new technologies integrated. So there is a need for more research in creating an IoT architecture to be used in water distribution system.

\section{CONCLUSION}

Water quality is a serious factor that affects the health of the economy. The increase in the number of IoT devices and the development of new technology requires a standard IoT architecture which could help the clients to create a low cost and efficient system. This paper discusses about the implementation of IoT in water distribution system on the basis of IoT architecture, upcoming technologies such as cloud computing, Artificial intelligence, transmission techniques etc.; applications and the advantage of IoT in water distribution. The paper reveals some of the current issues when selecting parameters for the smart water system. The paper also suggests some solutions by referring to the recent or upcoming researches which could resolve the issues and integrate them to produce a more cost and energy efficient smart water system. The paper also provides a comparison of energy harvesting methods and water quality sensors used in the current water pipelines to select the best method suitable for the application. The basic architecture of IoT lacks a proper structure and requires more research for developing and implementing an architecture and integrate it into the water distribution system.

\section{Challenges AND Future WORK}

As IoT is growing every day with new technologies involved, new challenges arise. The IoT has encouraged people to connect to devices using the internet and the increase in the use of IoT devices motivated people to use smart technologies. The water quality in the distribution system is a serious factor that affects public health and smart water 
system provides a user-friendly interface to monitor the water quality in houses and take remedial measurements if necessary. One of the main challenges in smart water system is managing the cost, energy and efficiency required for water distribution system. The selection of water quality, quantity and topological parameters is another challenge in the smart water system. So there is in need of research about these challenges to provide a new cost and energy efficient solution to the smart water system. The future work will focus on developing an IoT architecture in water distribution system with integration of new technologies such as cloud, energy harvesting etc.

\section{ACKNOWLEDGMENT}

This research is supported by European Union's Horizon 2020 research and innovation programme under the Marie Skłodowska-Curie-Innovative Training Networks (ITN)IoT4Win (765921).

\section{REFERENCES}

[1] Z. Zude, L. Quan, A. Qingsong, \& X. Cheng, "Intelligent monitoring and diagnosis for modern mechanical equipment based on the integration of embedded technology and FBGS technology". pp 1499 1511. $12 \quad$ Nov. 2011. https://doi.org/10.1016/j.measurement.2011.05.018

[2] J.M.P. Martinez, R.B. Llavori, M.J.A. Cabo, and T.B. Pedersen, "Integrating Data Warehouses with Web Data: A Survey," IEEE Trans. Knowledge and Data Eng., preprint, 21 Dec. 2007, doi:10.1109/TKDE.2007.190746.

[3] M. Zhang, F. Sun and X. Cheng, "Architecture of Internet of Things and Its Key Technology Integration Based-On RFID”, Proc IEEE Fifth International Symp. on computational intelligence and design, Oct. 2012, doi:10.1109/ISCID.2012.81.

[4] J. Lin, W. Yu, N. Zhang, X. Yang, H. Zhang, W. Zhao, "A survey on internet of things: Architecture enabling technologies security and privacy and applications", IEEE Internet of Things Journal, vol.4 (5), pp. 1125-1142, Oct. 2017.

[5] M. Wu, T. Lu, F. Ling, L. Sun, H. Du," Research on the architecture of Internet of things,", Advanced Computer Theory and Engineering (ICACTE), pp. 484-487, 2010.

[6] P. Hohenblum, "Workshop on early warning systems" (2014). Report of ERNCIP thematic area Chemical \& Biological Risks in the Water Sector Deliverable DI -Task 1. Retrieved from https://erncipproject.jrc.ec.europa.eu/sites/default/files/Review_of_sensors_to_mon itor_water quality.pdf, 26 Jun. 2014.

[7] K. Abhirami and L.R. Karlmarx. "A novel fault-tolerant control scheme for water distribution systems", Proc. IEEE Conference on Energy Efficient Technologies for Sustainability, Apr. 2013, doi: 10.1109/ICEETS.2013.6533496.

[8] T. P. Lambrou, C. C. Anastasiou, C. G. Panayiotou and M. M. Polycarpou, "A Low-Cost Sensor Network for Real-Time Monitoring and Contamination Detection in Drinking Water Distribution Systems". IEEE Sensors Journal, 14(8), 2765-2772, 2014.

[9] J. V.D. Broeke, "A short evaluation of the S::can Spectro::lyser", Evaluation Report project number111508.030, Kiwa, Netherlands, Jan. 2005.

[10] B. O’Flyrm, R. Martinez, J. Cleary, C. Slater, F. Regan, D. Diamond, H. Murphy, "SmartCoast: A wireless sensor network for water quality monitoring", $32^{\text {nd }}$ IEEE Conference on Local Computer Networks, Dublin, 15 Oct. 2007.

[11] T. Mcdougle, M. Maurel, C. Lemoine, "Smart sensor network case study for drinking water quality monitoring", Researchgate, Conference of International water association, Korea, Jan. 2012.

[12] Libelium, "Smart water sensors to monitor water quality in rivers, lakes and the sea”, Retrieved March 26, 2018, http://www.libelium.com/smart-water-sensors-to-monitor-waterquality-in-rivers-lakes-and-the-sea/
[13] A. Tsopela, A. Laborde, L. Salvagnac, V. Ventalon, E. Bedel-Pereira, I. Seguy, P. Temple-Boyer, P. Juneau, R. Izquierdo, J. Launay, "Development of a lab-on-chip electrochemical biosensor for water quality analysis based on microalgal photosynthesis", Journal of Biosensors and Bioelectronics, ScienceDirect, vol.79, pp. 568-573, Dec. 2015.

[14] S. Kosunalp, "A New Energy Prediction Algorithm for EnergyHarvesting Wireless Sensor Networks with Q-Learning”, In IEEE Access, vol. 4(1), 7 Sept. 2016

[15] N. A. Bhatti, M. H. Alizai, A. A. Syed \& L. Mottola., "Energy Harvesting and Wireless Transfer in Sensor Network Applications". ACM Transactions on Sensor Networks, 12(3), 1-40, 15Nov. 2015. https://doi.org/10.1145/2915918

[16] P. K. Sharma and P. V. Baredar, "Analysis on piezoelectric energy harvesting small scale device- a review", Journal of king saud university, ScienceDirect, 22 Nov. 2017.

[17] K Chang J Gao WY Wu, "Water quality comprehensive evaluation method for large distribution network based on clustering analysis". International Journal of Hydroinformatics 13(3) 2011 p390-400 doi: 10.2166/hydro.2011.021

[18] M. I. Mohamed; W. Y. Wu; M. Moniri, Adaptive data compression for energy harvesting wireless sensor nodes, 10th IEEE International Conference On Networking, Sensing And Control (ICNSC), Pages: $633-638$, France 2013

[19] M. I. Mohamed, W. Wu \& M. Moniri, "Power harvesting wireless sensor node framework for monitoring water distribution systems". In eleventh international conference on computing and control for water industry CCWI 2011 Exeter UK

[20] [21] F. Yang, W. Y. Wenyan, "An IoTs enabled Framework for Urban water system". In E-proceedings of the 36th IAHR World Congress 28 June - 3 July, 2015(id: 87075) IAHR2015.

[21] M. I. Mohamed, W. Y. Wu, \& M. Moniri, "Power harvesting for smart sensor networks in monitoring water distribution system". In 2011 International Conference on Networking, Sensing and Control, IEEE, pp. 393-398. 16 Nov. 2011

[22] F. U. Qureshi, A. Muhtaroglu, \& K. Tuncay, "A method to integrate energy harvesters into wireless sensor nodes for embedded in-pipe monitoring applications". In 5th International Conference on Energy Aware Computing Systems \& Applications, IEEE, pp. 1-4. 18 Oct. 2015

[23] F. U. Qureshi, A. Muhtaroglu, \& K. Tuncay, "Near-Optimal Design of Scalable Energy Harvester for Underwater Pipeline Monitoring Applications with Consideration of Impact to Pipeline Performance". IEEE Sensors Journal, 17(7), pp.1981-1991. 1 Apr. 2017.

[24] M. Jurian, C. Panait, V. Daniel, C. Bogdan, "Monitoring drinking water quality and wireless transmission of parameters", Proc IEEE International Spring Seminar on Electronics Technology, 12 Aug. 2010, doi: 10.1109/ISSE.2010.5547352.

[25] M. Pule, A. Yahya, J. Chuma, "Wireless Sensor Network: A survey on monitoring water quality", J. Applied Research and Technology, vol.15(6), pp.562-570, Dec. 2017.

[26] S. A. Sarawi, M. Anbar, K. Alieyan, M. Alzubaidi, "Internet of Things(IoT) communication proocols: Review", Proc. IEEE International conf. on Information Technology, 23 Oct. 2017.

[27] M. U. Farooq, M. Waseem, S. Mazhar, A. Khairi, T. Kamal, "A Review on Internet of Things (IoT)", International journal of Computer Applications, vol.113(1), March 2015.

[28] Z. Fu, J. Cheng, M. Yeng, J. Batists, "Prediction of industrial wastewater quality parameters based on wavelet de-noised ANFIS model", Proc of IEEE 2018 Annual computing and communication workshop and conference (CCWC '08), 27 Feb. 2018.

[29] J. Wan, M. Huang, Y. Ma, W. Guo, Y. Wang, H. Zhang, W. Li, X. Sun, "Prediction of effluent quality of a paper mill wastewater treatment using an adaptive network-based fuzzy inference system", Applied Soft Computing, vol. 11, no. 3, pp. 3238-3246, 2011.

[30] A. H. Zare, "Evaluation of multivariate linear regression and artificial neural networks in prediction of water quality parameters", Journal of Environmental Health Science \& Engineering, vol. 12, no. 1, pp. 1-8, 2014.

[31] S. K. Alshattnawi, "Smart Water Distribution Management System Architecture Based on Internet of Things and Cloud Computing", IEEE International conference on new trends in computing sciences, pp. 289294, 11 Jan. 2018. 
[32] A. C. Niel, M. Reza, N. Lakshmi, “ Design of Smart Sensors for RealTime Water Quality Monitoring”. J IEEE Access 4: 3975-3990, 2016.

[33] P. Thinagaran, S. Nasir, C. Y. Leong, "Internet of Things (IoT) enabled water monitoring system". In: 4 IEEE global conference on consumer electronics, 27-30 Oct. 2015.

[34] P. Yang., Hanneghan, M., Qi, J., Deng, Z., Dong, F. and Fan, D., 2015, October. "Improving the validity of lifelogging physical activity measures in an internet of things environment". In Computer and Information Technology; Ubiquitous Computing and Communications; Dependable, Autonomic and Secure Computing; Pervasive Intelligence and Computing (CIT/IUCC/DASC/PICOM), 2015 IEEE International Conference on (pp. 2309-2314). IEEE.

[35] Y. Ye, L. Liang, H. Zhao, Y.Jiang, "The system architecture of Smart Water grid for Water security", In Elsevier $12^{\text {th }}$ International Conference on Hydroinformatics (HIC), December 2016.

[36] R. Wright, E. Abraham, P. Parpas and I. Stoianov, "Control of water distribution networks with dynamic DMA topology using strictly feasible sequential convex programming". In Water resorce research AGU journal, 51(12), pp.9925-9941, December 2015.

[37] J. Pacheco, D. Ibarra, A. Vijay, S. Hariri, "IoT security framework for Smart Water System", Proc. of IEEE International conference on Computer Systems and Applications, Tunisia, 12 Mar. 2018.

[38] A. N. Prasad, K.A. Mamun, F.R. Islam, H. Haqva, "Smart water quality monitoring system", Proc. of IEEE Asia-Pacafic World Congress on Computer Science and Engineering, Fiji, 23 May 2016.

[39] G. S. Menon, M. V. Ramesh, P. Divya, "A low cost wireless sensor network for water quality monitoring in natural water bodies", In IEEE Global Humanitarian Technology Conference, USA, 25 Dec. 2017.

[40] Y. Wu, K. Kim, M. F. Henry, K.Y. Toumi, "Design of a leak sensor for operating water pipe systems", In IEEE International Conference on Intelligent Robots and Systems, Canada, 14 Dec. 2017.

[41] M.V. Ramesh, K.V. Nibi, A. Kurup, R. Mohan, A. Aiswarya, A. Arsha, P.R. Sarang, "Water quality monitoring and waste management using IoT", In IEEE Global Humanitarian Technology Conference, USA, 25 Dec. 2017.

[42] J. Qi, P. Yang, G. Min, O. Amft, F. Dong and L. Xu. "Advanced internet of things for personalised healthcare systems: A survey". Pervasive and Mobile Computing, 41, pp.132-149. 2017.

[43] O. Pandithurai, S. Aishwarya, B. Aparna, K. Kavitha, "Agro-tech: A digital model for monitoring soil and crops using internet of things (IOT)", Proc. of IEEE International conference on Science, Technology, Engineering and Management, India, 18 Jan. 2018.

[44] S. Vaishali, S. Suraj, G. Vignesh, S. Dhivya, S. Udhayakumar, "Mobile integrated smart irrigation management and monitoring system using
IOT", Proc. of IEEE International conference on Communication and Signal Processing, India, 08 Feb. 2018.

[45] K. Lekjaroen, R. Ponganantayotin, A. Charoenrat, S. Funilkul, U. Supasitthimethee, T. Triyason, "IoT Planting: Watering system using mobile application for the elderly", Proc. IEEE International Computer science and Engineering Conference, Thailand, 23 Feb. 2017, doi:10.1109/ICSEC.2016.7859873.

[46] M. Manju, V. Karthik, S. Hariharan, B. Sreekar, "Real time monitoring of the environmental parameters of an aquaponic system based on Internet of Things", Proc. of IEEE International conference on Science, Technology, Engineering and Management, India, 18 Jan. 2018.

[47] B. Zhou, C. Bian, J. Tong, S. Xia, "Fabrication of a miniature multiparameter sensor chip for water quality assessement", Journal of Sensors, vol. 17(1), 14 Jan. 2017.

[48] D. Nguyen, \& P. H. Phung, "A Reliable and Efficient Wireless Sensor Network System for Water Quality Monitoring". In IEEE 2017 International Conference on Intelligent Environments (IE), pp. 84-91. https://doi.org/10.1109/IE.2017.34

[49] T. A. Janabi and H. S. Al-Raweshidy, "Optimised clustering algorithm based centralised architecture for load balancing in IoT network". In IEEE 2017 International symposium on Wireless Communication Syatems, Italy, 16 Nov. 2017.

[50] D. Macci, A. Boni, M. De Cecco, D. Petri, Tutorial 14: Multisensor Data Fusion. IEEE Instrum. Meas. Mag. vol. 11 ,pp 24-33, Jun. 2008.

[51] W. Ejaz, M. Naeem, M. Basharat, A. Anpalagan, \& S. Kandeepan, "Efficient Wireless Power Transfer in Software-Defined Wireless Sensor Networks". In IEEE Sensors Journal, 16(20), 7409-7420, 12 Nov. 2016. https://doi.org/10.1109/Jsen.2016.2588282

[52] S. Nikoletseas, T. Raptis, A. Souroulagkas, \& D. Tsolovos, "Wireless Power Transfer Protocols in Sensor Networks: Experiments and Simulations". In Journal of Sensor and Actuator Networks, 6(2), 4, 1 Apr. 2017. https://doi.org/10.3390/jsan6020004. 